\title{
Germinação e vigor de sementes de alfavaca-cravo (Ocimum gratissimum L.) submetidas ao envelhecimento acelerado
}

\section{Germination and vigor of clove basil seeds (Ocimum gratissimum $\mathrm{L}_{\text {.) }}$ submitted to accelerated aging}

\author{
Cristina Batista de Lima ${ }^{1}$; João Carlos Athanázio²; Nair Mieko Takaki Bellettini ${ }^{*}$
}

\begin{abstract}
Resumo
O presente trabalho teve como objetivo verificar o efeito do período de exposição, tipos de solução e tratamento com fungicida sobre a germinação e o vigor de quatro lotes de sementes de alfavaca-cravo, submetidas ao teste de envelhecimento acelerado tradicional e com uso de solução saturada de $\mathrm{NaCl}$, por períodos de $36,48,60$ e 72 horas na temperatura de $42^{\circ} \mathrm{C}$. Após estes períodos, as sementes foram avaliadas pelo teste de germinação, utilizando-se a primeira contagem do teste de germinação como indicativo de vigor. Tanto o vigor quanto a germinação das sementes analisadas, diminuíram conforme se aumentou o tempo de envelhecimento. Na utilização de solução salina, o teor e a variabilidade de água das sementes foram menores. O tratamento fungicida aumentou a média percentual de germinação, mas não provocou modificações acentuadas nos contrastes entre os lotes. Os períodos de 36 e 48 horas foram eficientes na avaliação da qualidade fisiológica das sementes de alfavaca-cravo.

Palavras-chave: Potencial fisiológico, fungos, plantas medicinais
\end{abstract}

\begin{abstract}
The present work had as objective to verify the effect of treatment with fungicide on the germination and vigor of four lots of clove basil seeds, submitted to the traditional aging and with saturated salt solution, for periods of $36,48,60$ and 72 hours, at $42^{\circ} \mathrm{C}$. After these periods, the seeds were evaluated by the germination test, using the first count of the number of normal seedlings as vigor indicative. The vigor and the germination of the seeds decreased as increased the time of aging. In the use of saturated salt solution, the seeds water content was lower and more uniform. The fungicide treatment increased the percentage average of germination, without provoking significant modifications in the contrasts among the lots. The periods of 36 and 48 hours were efficient in evaluating of the physiologic quality of the clove basil seeds.
\end{abstract}

Key words: Physiological potential, fungus, medicinal plants

1 Eng Agr., Doutoranda do Curso de Agronomia da Universidade Estadual de Londrina (UEL); Docente do Depto de Produção Vegetal da Fundação Faculdades “Luiz Meneghel”, Bandeirantes, Paraná. E-mail: crislima@ffalm.br.

2 Eng Agr., Dr. Prof do Centro de Ciências Agrárias da Universidade Estadual de Londrina (UEL), Londrina-PR. E-mail: jcatha@uel.br.

3 Eng Agra ${ }^{a}$ Dra. Docente do Departamento de Produção Vegetal da FFALM. E-mail: nair@ffalm.br

* Autor para correspondência. 


\section{Introdução}

Registros da medicina romana, egípcia, persa e hebraica mostram que desde os tempos remotos, o homem usa o poder terapêutico das plantas medicinais de forma extensiva para curar praticamente todas as doenças conhecidas (MENEGHELLO; SCHNEIDER; LUCCA-FILHO, 2002). A demanda por tais plantas, através do extrativismo reduziu o patrimônio vegetal (CORRÊA JÚNIOR, 2001), fazendo com que se desenvolvessem técnicas racionais de cultivo, a ponto de encontrarem-se relacionadas nas Regras de Análise de Sementes (RAS) metodologias para análise de sementes de algumas dessas espécies. Estas plantas são merecedoras de estudos, não somente quanto à identificação e descrição correta do princípio ativo fitoterápico, mas também, em relação a seu comportamento germinativo (ROSA; FERREIRA, 1998).

Nóbrega et al. (1995) descrevem que o cultivo em escala comercial da camomila (Matricaria recutita $\mathrm{L}$.), apresenta dificuldades devido à densidade irregular da cultura no campo, sendo esta decorrente da utilização de sementes com baixa qualidade. Meneghelo, Schneider e Lucca-Filho, (2002) avaliaram sementes de cinco espécies medicinais comercializadas, concluindo que a porcentagem de germinação indicada nas embalagens superestima a qualidade das mesmas e há poucas informações adicionais no que se refere a possível existência de dormência e como superá-la.

Uma alta porcentagem inicial de germinação não implica necessariamente na manutenção da qualidade de um lote de sementes durante o período de armazenamento, nem que suas plântulas irão se desenvolver satisfatoriamente depois de semeadas no campo. Apresenta-se então o vigor como uma medida real do grau de deterioração de sementes, considerando-se que ele pode estimar sua capacidade de sobrevivência às condições de plantio e as de armazenamento (KRZYZANOWSKI, 1974).
O desenvolvimento de uma técnica para se estimar o vigor que seja de fácil execução, com possibilidade de ser padronizada e que revele dados consistentes e uniformes, é imprescindível num esquema de controle de qualidade em qualquer sistema de produção de sementes. Dentre os métodos propostos, o chamado envelhecimento rápido, precoce, acelerado ou simplesmente envelhecimento, demonstra ser promissor e de interesse prático. Este teste foi desenvolvido pôr Delouche (1965), que em trabalhos subseqüentes, armazenou sementes de várias espécies para observar seu comportamento (DELOUCHE; HELMER, 1967; RUSHING, 1969). Em 1973, Delouche e Baskin estudaram a previsão de armazenamento para 16 espécies utilizando este processo (DELOUCHE; BASKIN, 1973).

No Brasil, o envelhecimento acelerado vem sendo aplicado em pesquisas desde 1971 com excelentes resultados (MELLO; TILLMANN, 1987). Baseia-se no princípio de que lotes com alto vigor manterão sua viabilidade, enquanto que nos de baixo vigor será reduzida, quando submetidos durante curtos períodos de tempo a condições severas de temperatura e umidade relativa do ar, em uma câmara apropriada (RODO; PANOBIANCO; MARCOS FILHO, 2000). Este teste é recomendado para diversas culturas, porém existem fatores como teor de água inicial das sementes, controle da umidade relativa do ar na câmara de envelhecimento, espécie, cultivar, tempo de exposição e realização de tratamento fungicida que interferem na uniformização da sua metodologia (MARCOS FILHO; SHIOGA, 1981; MELLO; TILLMANN, 1987; IRIGON; ROSSINI, 1992; SANTOS et al., 2002).

Para as plantas que possuem sementes pequenas, a desuniformidade dos resultados obtidos retrata a dificuldade de reproduzi-los, restringindo seu uso e inviabilizando sua padronização (MELLO; TILLMANN, 1987). Estas sementes, em razão de apresentarem menores quantidades de reservas, estão propensas a acentuada deterioração após a 
maturidade fisiológica, tanto que, habitualmente são acondicionadas em embalagens herméticas ou em ambientes especiais sob temperatura e/ou umidade relativa controladas (PANOBIANCO; MARCOS FILHO, 2001). Além disso, a rápida absorção de água pôr essas sementes, leva a diminuição drástica da germinação pós-envelhecimento (POWELL, 1995).

Segundo Rosseto e Marcos Filho (1995), o grau de umidade é um dos fatores que afetam o comportamento das sementes durante os testes de vigor. Marcos Filho (1999) cita que diferenças de 1 a $2 \%$ na umidade inicial entre as amostras são admitidas, e que variações acentuadas, provocam mudanças na velocidade de umedecimento e na intensidade de deterioração, pois sementes muito úmidas são mais sensíveis à alta temperatura e umidade relativa do ar que ocorrem durante o teste, favorecendo na germinação plântulas anormais e mortas. Após o envelhecimento acelerado são aceitáveis diferenças de até $4 \%$, já que o grau de umidade final da semente, é um dos principais indicadores de uniformidade durante sua execução.

Miranda, Novembre e Chamma (2001), testando várias temperaturas e números de horas de envelhecimento relatam que para um determinado período de exposição, a semente de sorgo alcança maior teor de água nas menores temperaturas, porém, para uma mesma temperatura, o aumento do período de exposição proporciona ganho de um a dois pontos percentuais no teor de água dessas sementes. Para contornar este fator, tem sido sugerido o uso de soluções saturadas de sais durante a realização do teste, pôr reduzirem a umidade relativa no interior dos compartimentos individuais $(\mathrm{NaCl}-76 \% \mathrm{UR}, \mathrm{KCl}$ - $87 \%$ UR ou $\mathrm{NaBr}-55 \% \mathrm{UR})$, retardando a absorção de água pelas sementes. Este método, denominado teste de envelhecimento acelerado com uso de soluções saturadas de sal (SSAA - "Saturated Salt Accelerated Aging") foi proposto pôr Jianhua e McDonald (1996), que trabalhando com sementes de Impatiens wallerana Hook, descreveram a eficiência desse tipo de solução no controle da absorção de água pelas sementes e na avaliação do vigor.
Martins et al. (2002), aplicaram diferentes testes de vigor com variações nas metodologias, na avaliação da qualidade de sementes de couvebrócolos e Torres (2004), com de erva doce, observaram que aquelas submetidas ao envelhecimento modificado com solução salina absorveram quantidade de água inferior em relação as que foram expostas ao teste normal com água, controlando a taxa de absorção e a velocidade de deterioração.

Quanto à temperatura e aos períodos adequados de exposição a esse teste, apesar de diversos estudos terem sido conduzidos, não se chegou a um consenso entre os pesquisadores, existindo carência de informações para várias espécies de importância econômica. Apesar da descrição do teste citar a possibilidade da utilização de temperaturas de 40 a $45^{\circ} \mathrm{C}$, durante muitos anos predominou a recomendação de $42^{\circ} \mathrm{C}$ e recentemente, grande parte dos pesquisadores passaram a adotar $41^{\circ} \mathrm{C}$ (MARCOS FILHO, 1999).

Baggio et al. (2003), verificaram a influência de diferentes números de horas do teste de envelhecimento acelerado sobre a germinação de sementes de orégano e erva de gato, com intervalos de zero, $12,24,36,48,60,72$ e 84 horas a uma temperatura de $42^{\circ} \mathrm{C}$. Para as duas espécies percebeu-se um declínio no percentual germinativo, conforme o aumento no número de horas de exposição, atingindo em 84 horas $0 \%$ para orégano e $13 \%$ para erva de gato. Em ambos os casos, 48 horas foi suficiente para se verificar diferenças entre amostras.

Predominam na literatura, pesquisas em que após tentativas de uso de vários períodos de exposição, recomenda-se o que foi capaz de detectar diferenças de vigor entre amostras avaliadas, ainda que, esse período possa causar níveis de estresse muito drásticos que os enfrentados pelas sementes durante o transporte, armazenamento ou em condições de campo. Na realidade, o teste é eficiente mesmo que não consiga identificar diferenças entre as amostras 
avaliadas, pois as mesmas podem apresentar níveis semelhantes de vigor (MARCOS FILHO, 1999).

No tocante a incidência de fungos, Marcos Filho (1994) ressalta que temperaturas e umidade elevadas podem inibir a manifestação de alguns microorganismos, de tal forma que os dados obtidos no envelhecimento, podem ser superiores aos do teste padrão de germinação. Para Silva e Silva (2000), as respostas obtidas com sementes de feijão pósenvelhecimento indicaram efeitos da espécie fúngica presente, que prejudicou a interpretação dos dados obtidos, devido ao teste associar a expressão de causas fisiológicas e sanitárias. Segundo esses autores, a presença de fungos pode ser considerada como capaz de interferir de modo negativo, no desempenho das sementes envelhecidas artificialmente.

Kostetzer et al. (2004a) relataram a presença de fungos em sementes de camomila. Durante o envelhecimento acelerado houve diminuição da diversidade e aumento na proporção dos mesmos, em relação à testemunha. Kostetzer et al. (2004b), com mesmo procedimento em sementes de erva cidreira verdadeira, verificaram influências na quantidade e variedade dos fungos encontrados a ponto de impedirem a germinação das sementes em alguns tratamentos.

No trabalho de Leite et al. (2004) sementes de espinheira santa, apresentaram diversos tipos de fungos após a exposição a diferentes intervalos de envelhecimento acelerado. Berthi et al. (2004), também analisaram o desempenho de sementes dessa espécie a esse teste e concluíram que o desenvolvimento de fungos influenciou negativamente a germinação das sementes.

Jianhua e McDonald (1996) e Rodo et al. (2000) destacam que o emprego de soluções saturadas de sal no teste de envelhecimento acelerado pode manter os valores de umidade relativa do ar em níveis suficientes para impedir o crescimento de microrganismos minimizando, a preocupação com efeitos de patógenos associados às sementes sobre os dados coletados.
A espécie Ocimum gratissimum L., popularmente conhecida como alfavaca ou alfavaca-cravo é originária da Ásia e subespontânea no Brasil (LORENZI; MATOS, 2002). Trata-se de um subarbusto com flores, frutos e pequeninas sementes reunidos em numerosas inflorescências. Possui cheiro típico que lembra o cravo-da-índia, o que a torna facilmente reconhecida. Seu óleo essencial rico em eugenol, confere ação anti-séptica local contra fungos (Aspergillus, Trichoderma) e bactérias (Staphylococcus). É empregado como anestésico odontológico, na síntese de acetato em perfumaria e aromatizante nas indústrias de bebidas (CRAVEIRO et al., 1981). A planta é indicada no tratamento de gripes, tosses, irritações da garganta e aromatizante bucal (MATTOS et al., 2000).

O presente trabalho teve como objetivos verificar a influência do período de exposição, tipos de solução e tratamento fungicida durante o teste de envelhecimento acelerado, sobre a germinação e o vigor de sementes de alfavaca-cravo.

\section{Material e Métodos}

O trabalho foi conduzido no período de Julho a Agosto de 2004, no Laboratório de Análise de Sementes do Departamento de Produção Vegetal, da Fundação Faculdades "Luiz Meneghel” (FFALM), em Bandeirantes-PR.

Foram utilizados quatro lotes de sementes de alfavaca-cravo, coletadas durante o segundo semestre de 2003 e o primeiro de 2004, a partir de plantas matrizes cultivadas na área experimental da FFALM.

Após as colheitas, as sementes foram limpas, beneficiadas, acondicionadas em sacos de papel Kraft e armazenadas sob temperatura de $6-10^{\circ} \mathrm{C}$ até o início do experimento.

A determinação do grau de umidade foi feita antes e imediatamente após o teste de envelhecimento acelerado nos dois procedimentos, com 4,0 g de sementes de cada lote. Utilizou-se o método da estufa 
a $105 \pm 3^{\circ} \mathrm{C}$, durante 24 horas conforme as Regras para Análise de Sementes-RAS (BRASIL, 1992), sendo os resultados expressos em porcentagem.

De cada lote, retirou-se 2 sub-lotes de sementes para serem submetidas a tratamentos com fungicida (Captan 750 PM (N-[(triclorometil) tio]-4ciclohexeno-1,2-dicarboximida), na dose de 2,1 g do produto/kg de sementes) e sem fungicida. Cada sublote totalizou 3600 sementes, para os tratamentos do teste de envelhecimento acelerado e 36 gramas de sementes para determinação da umidade.

Para os testes de envelhecimento acelerado, empregou-se caixas plásticas tipo "Gerbox" (como compartimento individual - mini câmara). No procedimento com água, utilizou-se de cada sub-lote, 2 amostras de 400 sementes, que foram distribuídas em camada uniforme, cada uma sobre tela metálica, acoplada aos recipientes, contendo $40 \mathrm{~mL}$ de água destilada ao fundo e mantidas sob temperatura de $42^{\circ} \mathrm{C}$ em câmara de germinação, nos períodos zero (testemunha), 36, 48, 60 e 72 horas. No envelhecimento acelerado com sal, aplicou-se o proposto pôr Jianhua e McDonald (1996).

As sementes que apresentaram fungos após o teste de envelhecimento acelerado passaram por uma desinfestação em solução a $1 \%$ de hipoclorito de sódio sendo a seguir, lavadas com água destilada para o teste de germinação.

Os recipientes "Gerbox" e utensílios de alumínio utilizados no trabalho foram imersos em solução de hipoclorito de sódio a 3\%, por 12 horas, posteriormente enxaguados em água destilada e desinfestados com álcool etílico a 70\%.

O teste de germinação foi conduzido com 4 repetições de 100 sementes para cada lote, distribuídas eqüidistantes sobre papel filtro em recipientes plásticos "Gerbox" e colocadas para germinar a $25^{\circ} \mathrm{C}$, em regime de luz. As avaliações foram efetuadas no $6^{\circ}$ e $14^{\circ}$ dia após a instalação, seguindo-se o sugerido por Rocha et al. (2000).
O papel filtro utilizado para o teste de germinação foi esterilizado em autoclave e umedecido com água destilada equivalente a 2,5 vezes o peso do papel seco. A umidade no interior dos recipientes foi monitorada diariamente. As plântulas normais foram contadas e retiradas do substrato. Para evitar alteração na definição das plântulas normais, foi préestabelecido o tamanho (parte aérea e radicular) em no mínimo, 1 centímetro de comprimento.

A primeira contagem da germinação através do registro do número de plântulas normais no sexto dia após a instalação do teste de germinação foi utilizada como teste de vigor. Segundo Barros (2002), a velocidade de germinação é reduzida com o avanço da deterioração da semente. Assim, amostras que apresentam maiores valores de germinação na primeira contagem podem ser consideradas mais vigorosas.

No procedimento estatístico adotado, o delineamento experimental para avaliação do teste de envelhecimento acelerado, foi o inteiramente casualizado com duas repetições, em esquema fatorial 4x5x2 (lotes x períodos de exposição x tipo de solução) analisados separadamente para avaliação do tratamento fungicida. Os dados referentes ao grau de umidade não foram submetidos à análise estatística, servindo para a caracterização inicial e monitoramento dos lotes após o envelhecimento acelerado. Na verificação da qualidade fisiológica das sementes, as médias originais obtidas nas avaliações foram analisadas pelo teste de Tukey, a $5 \%$ de probabilidade. No estudo do efeito dos períodos em horas de exposição ao envelhecimento acelerado, empregou-se análise de regressão polinomial, utilizando-se efeito quadrático de acordo com a significância pelo teste $\mathrm{F}$, a 5\% de probabilidade.

\section{Resultados e Discussão}

As sementes do lote 1 tiveram umidade inicial superior em relação aos demais (Tabela 1), não ultrapassando, entretanto, a faixa de variação indicada por Marcos Filho (1999), como sendo viável, sem 
que haja influência nos resultados. No envelhecimento acelerado realizado de acordo com o protocolo tradicional, é visível o aumento considerável nas diferenças de umidade entre os lotes, atingindo valores muito acima daqueles preconizados por Marcos Filho (1999). Os lotes 1, 2 e 4 nos períodos 48, 60 e 72 horas e o lote 3 no período de 36 horas, apresentaram contaminação por fungos ao final do envelhecimento acelerado tradicional, independente do tratamento fungicida. Além disso, conforme se aumentou o período de exposição das sementes ao envelhecimento, houve um incremento no teor de água de cada lote, fato este também relatado pôr Miranda, Novembre e Chamma (2001).

Tabela 1. Teor de água (\%) inicial e após envelhecimento acelerado nos procedimentos tradicional (EAA) e com solução salina (EAS) de quatro lotes de sementes de alfavaca cravo.

\begin{tabular}{llcccc}
\hline \multirow{2}{*}{ Teor de água } & \multicolumn{5}{c}{ Lotes } \\
\cline { 2 - 6 } & & 1 & 2 & 3 & 4 \\
\hline Inicial & 8,4 & 7,7 & 7,3 & 7,0 \\
& & & & & 31,7 \\
\multirow{3}{*}{ EAA } & 36 horas & 34,3 & 33,3 & 34,8 & 37,2 \\
& 48 horas & 41,2 & 39,0 & 38,7 & 45,4 \\
& 60 horas & 46,9 & 44,2 & 47,3 & 11,1 \\
\multirow{3}{*}{ EAS } & 72 horas & 55,4 & 53,3 & 52,2 & 11,0 \\
& 36 horas & 11,4 & 10,8 & 11,2 & 11,4 \\
& 48 horas & 11,6 & 10,8 & 11,0 & 11,4 \\
\hline
\end{tabular}

O uso de solução saturada de $\mathrm{NaCl}$ promoveu a redução na captação de água pelas sementes, de modo que ao final dos tempos estudados, atingiram percentuais inferiores aos do protocolo tradicional, mantendo-se dentro dos limites admissíveis. No protocolo tradicional independente do tratamento fungicida, todos os lotes foram contaminados, confirmando o exposto nos trabalhos de Marcos Filho e Shioga (1981), Leite et al. (2004), Kostetzer et al. (2004a) e Kostetzer et al. (2004b). Após o envelhecimento com solução de $\mathrm{NaCl}$ não se constatou proliferação de fungos, efeito já ressaltado por Jianhua e MacDonald (1996) e Rodo et al. (2000), como um importante benefício dessa técnica.

O parâmetro vigor, associado ao procedimento com $\mathrm{NaCl}$, possibilitou identificar os lotes 1 e 3 como o de maior e menor qualidade fisiológica, respectivamente (Tabela 2), com resultado análogo observado por Torres (2004).

Com relação ao tempo de exposição ao teste, 72 horas diminuiu notadamente as médias de germinação, todavia pesquisas desse gênero como as de Torres e Marcos Filho (2001), Martins et al. (2002), Rodo e Marcos Filho (2003) e Torres (2004) apontam esse intervalo como opção promissora para avaliação do potencial fisiológico de sementes das espécies estudadas. Os períodos de 36 e 48 horas permitiram separar os lotes em níveis diferentes de vigor, sem causar estresses danosos à germinação. Resultados semelhantes foram relatados pôr Mello, Spinola e Minami (1999) e Baggio et al. (2003) que indicam 48 horas na condução desse teste.

O tratamento fungicida melhorou o desempenho das sementes avaliadas, corroborando com o observado por Rossetto et al. (2001). Ao contrário dos demais, o lote 3 apresentou fungos somente no período de 36 horas e mesmo assim, foi o menos vigoroso. Indicando que o nível de infestação não foi o principal responsável pelo alto número de sementes não germinadas. 


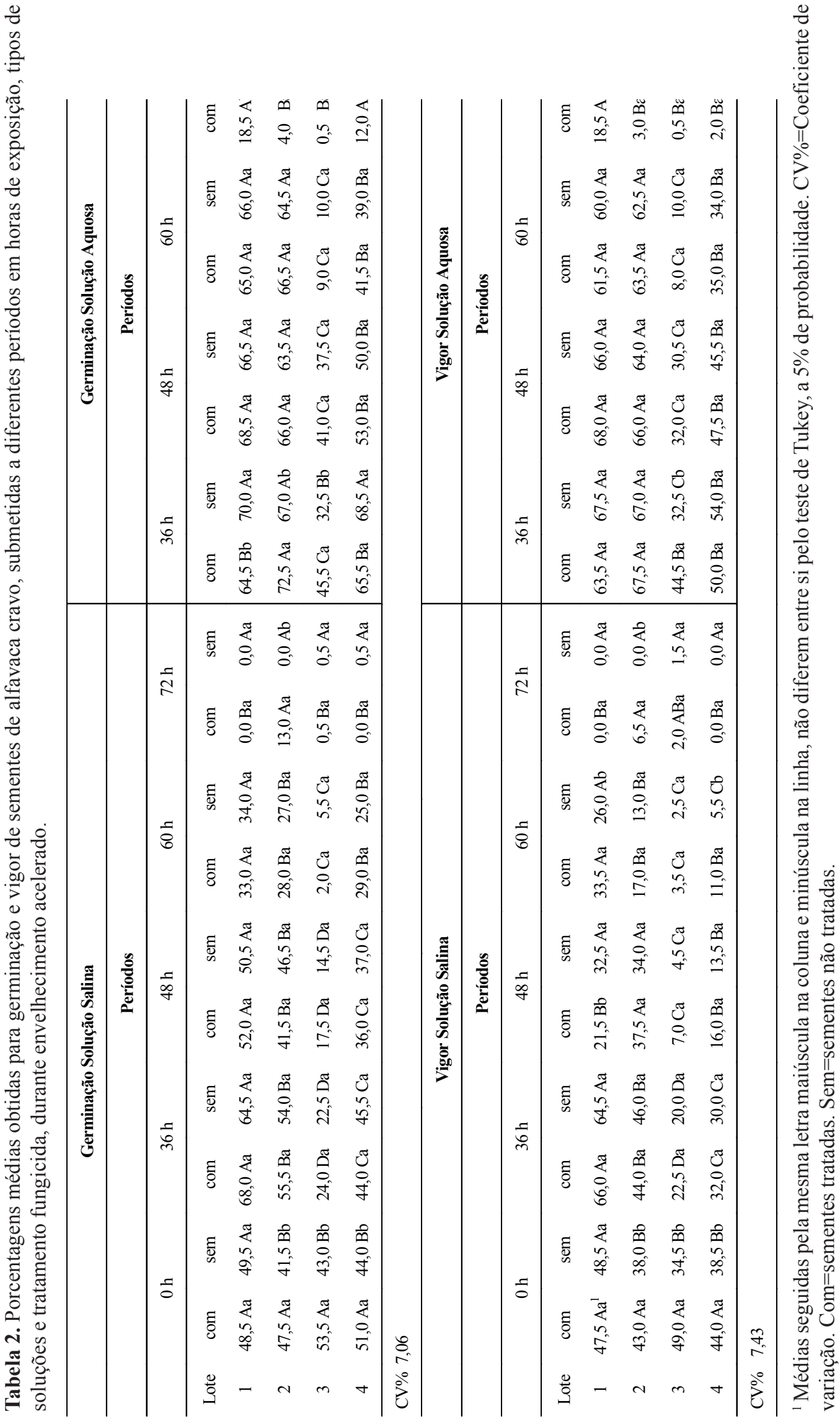

Semina: Ciências Agrárias, Londrina, v. 27, n. 2, p. 159-170, abr.jiun. 2006 
Apesar do envelhecimento acelerado tradicional ter proporcionado maior média percentual de vigor e germinação das sementes (Tabelas 3 e 4), esses parâmetros são influenciáveis e tendem a reduzir em ambos protocolos, à medida que se aumenta o número de horas sob as condições de estresse. Resultado semelhante foi descrito por Baggio et al. (2003). Tal comportamento pode ser ajustado por um polinômio de $2^{\circ}$ grau, com alto coeficiente de determinação, indicando que os modelos matemáticos selecionados mostraram uma boa aproximação do comportamento biológico, durante a condução do experimento.

Tabela 3. Equações ajustadas e coeficientes de determinação $\left(\mathrm{R}^{2}\right)$ para germinação de sementes de alfavaca cravo, submetidas a diferentes números de horas e tratamento fungicida durante envelhecimento acelerado nos procedimentos: tradicional (EAA) e com solução salina (EAS).

\begin{tabular}{|c|c|c|c|c|c|}
\hline Lotes & Fungicida & Procedimentos & Equação Ajustada & $\mathbf{R}^{2}$ & CV\% \\
\hline & Sem & EAA & $Y=-0,26 x^{2}+0,17 x+0,48$ & $0,85 x^{2 *}$ & 5,2 \\
\hline \multirow[t]{4}{*}{1} & & EAS & $Y=-0,25 x^{2}+0,11 x+0,50$ & $0,89 x^{2 *}$ & 7,9 \\
\hline & Com & EAA & $Y=-0,29 x^{2}+0,18 x+0,47$ & $0,79 x^{2 *}$ & 4,6 \\
\hline & & EAS & $Y=-0,27 x^{2}+0,14 x+0,48$ & $0,70 x^{2 *}$ & 5,3 \\
\hline & Sem & EAA & $Y=-0,37 x^{2}+0,21 x+0,41$ & $0,98 x^{2 *}$ & 4,5 \\
\hline \multirow[t]{4}{*}{2} & & EAS & $Y=-0,25 x^{2}+0,13 x+0,41$ & $0,99 x^{2 *}$ & 4,9 \\
\hline & Com & EAA & $Y=-0,38 x^{2}+0,21 x+0,47$ & $0,99 \mathrm{x}^{2 *}$ & 5,7 \\
\hline & & EAS & $Y=-0,20 x^{2}+0,95 x+0,48$ & $0,98 x^{2 *}$ & 5,6 \\
\hline & Sem & EAA & $Y=-0,12 x^{2}+0,30 x+0,43$ & $0,89 \mathrm{x}^{2 *}$ & 9,0 \\
\hline \multirow[t]{4}{*}{3} & & EAS & $Y=-0,21 x^{2}+0,73 x+0,43$ & $0,99 x^{2 *}$ & 12,3 \\
\hline & Com & EAA & $Y=-0,16 x^{2}+0,37 x+0,54$ & $0,94 x^{2 *}$ & 5,9 \\
\hline & & EAS & $Y=-0,18 x^{2}+0,89 x+0,54$ & $0,98 \mathrm{x}^{2 *}$ & 4,3 \\
\hline & Sem & EAA & $Y=-0,28 x^{2}+0,15 x+0,44$ & $0,97 \mathrm{x}^{2 *}$ & 6,8 \\
\hline \multirow[t]{3}{*}{4} & & EAS & $Y=-0,19 x^{2}+0,75 x+0,44$ & $0,99 x^{2 *}$ & 8,9 \\
\hline & Com & EAA & $Y=-0,26 x^{2}+0,13 x+0,51$ & $0,99 x^{2 *}$ & 3,6 \\
\hline & & EAS & $Y=-0,17 x^{2}+0,59 x+0,50$ & $0,95 x^{2 *}$ & 4,4 \\
\hline
\end{tabular}

* significativo a $5 \%$ de probabilidade; $\mathrm{x}^{2}=$ função quadrática; CV\%= coeficiente de variação. 
Tabela 4. Equações ajustadas e coeficientes de determinação $\left(\mathrm{R}^{2}\right)$ para vigor de sementes de alfavaca cravo, submetidas a diferentes números de horas e tratamento fungicida durante envelhecimento acelerado nos procedimentos: tradicional (EAA) e com solução salina (EAS).

\begin{tabular}{|c|c|c|c|c|c|}
\hline Lotes & Fungicida & Procedimentos & Equação Ajustada & $\mathbf{R}^{2}$ & CV\% \\
\hline \multirow{4}{*}{1} & \multirow{2}{*}{ Sem } & EAA & $Y=-0,29 x^{2}+0,18 x+0,47$ & $0,92 x^{2 *}$ & 7,2 \\
\hline & & EAS & $Y=-0,23 x^{2}+0,96 x+0,49$ & $0,93 \mathrm{x}^{2 *}$ & 6,4 \\
\hline & \multirow{2}{*}{ Com } & EAA & $Y=-0,28 x^{2}+0,18 x+0,46$ & $0,82 x^{2 *}$ & 4,0 \\
\hline & & EAS & $Y=-0,22 x^{2}+0,91 x+0,49$ & $0,73 x^{2 *}$ & 6,7 \\
\hline \multirow{4}{*}{2} & \multirow{2}{*}{ Sem } & EAA & $Y=-0,32 x^{2}+0,17 x+0,39$ & $0,95 \mathrm{x}^{2 *}$ & 3,1 \\
\hline & & EAS & $Y=-0,20 x^{2}+0,84 x+0,36$ & $0,97 \mathrm{x}^{2 *}$ & 4,8 \\
\hline & \multirow{2}{*}{ Com } & EAA & $Y=-0,29 x^{2}+0,15 x+0,44$ & $0,94 x^{2 *}$ & 7,3 \\
\hline & & EAS & $Y=-0,15 x^{2}+0,56 x+0,43$ & $0,97 \mathrm{x}^{2 *}$ & 7,2 \\
\hline \multirow{4}{*}{3} & \multirow{2}{*}{ Sem } & EAA & $Y=-0,11 x^{2}+0,32 x+0,35$ & $0,98 \mathrm{x}^{2 *}$ & 8,5 \\
\hline & & EAS & $Y=-0,51 x^{2}+0,11 x+0,49$ & $0,97 \mathrm{x}^{2 *}$ & 5,9 \\
\hline & \multirow{2}{*}{ Com } & EAA & $Y=-0,15 x^{2}+0,28 x+0,50$ & $0,95 x^{2 *}$ & 12,4 \\
\hline & & EAS & $Y=-0,33 x^{2}+0,72 x+0,35$ & $0,96 x^{2 *}$ & 10,5 \\
\hline \multirow{4}{*}{4} & \multirow{2}{*}{ Sem } & EAA & $Y=-0,27 x^{2}+0,15 x+0,38$ & $0,97 \mathrm{x}^{2 *}$ & 4,4 \\
\hline & & EAS & $Y=-0,28 x^{2}+0,36 x+0,39$ & $0,98 \mathrm{x}^{2 *}$ & 8,3 \\
\hline & \multirow[b]{2}{*}{ Com } & EAA & $Y=-0,24 x^{2}+0,12 x+0,43$ & $0,91 \mathrm{x}^{2 *}$ & 7,6 \\
\hline & & EAS & $Y=-0,51 x^{2}+0,26 x+0,44$ & $0,97 \mathrm{x}^{2 *}$ & 14,4 \\
\hline
\end{tabular}

*significativo a $5 \%$ de probabilidade; $\mathrm{x}^{2}=$ função quadrática; $\mathrm{CV} \%=$ coeficiente de variação.

\section{Conclusões}

Tanto germinação quanto o vigor das sementes de alfavaca-cravo, diminuíram conforme se aumentou o número de horas de envelhecimento acelerado.

Os intervalos de 36 e 48 horas a $42^{\circ} \mathrm{C}$ de envelhecimento acelerado aliados ao uso de solução salina, foram efetivos na avaliação da qualidade fisiológica dessas sementes.

Sementes submetidas à solução salina tiveram menor absorção de água e não apresentaram contaminação por fungos.

$\mathrm{O}$ tratamento fungicida melhorou o desempenho germinativo, todavia, não provocou modificações acentuadas nas diferenças entre os lotes.

\section{Referências}

BAGGIO, L.; LIMA, C. B.; SATO, O.; BUENO, J. T.; KOSTETZER, K.; LEITE, L. L.; BERTHI, D.; SILVA, M. Influência do número de horas de envelhecimento acelerado sobre as sementes de Nepeta cataria e Oreganum vulgare. Informativo ABRATES, Curitiba, v.13, n.3, p.416, set. 2003.

BARROS, D. I.; NUNES, H. V.; DIAS, D. C. F. S.; BHERING, M. C. Comparação entre testes de vigor para avaliação da qualidade fisiológica de sementes de tomate. Revista Brasileira de Sementes, Brasília, v.24, n.2, p.12-16, 2002.

BERTHI, D.; LIMA, C. B.; SATO, O.; BUENO, J. T.; LEITE, L. L.; SILVA, M.; KOSTETZER, V.; SOLDERA, M. C. A.; NOGUEIRA, L. M. Número de horas do teste de envelhecimento acelerado sobre a germinação e o vigor de sementes de Maytenus ilicifolia. Arquivos Apadec, Maringá, v.8, sup.1, n.28, p.29, out. 2004. 
BRASIL, Ministério da Agricultura e Reforma Agrária. Regras para análise de sementes. Brasília: Coordenação de Laboratório Vegetal - CLAV. Departamento Nacional de Defesa Vegetal, 1992.

CORRÊA JÚNIOR, C. Fundamentos do cultivo de plantas medicinais, condimentares e aromáticas. Horticultura Brasileira, Brasília, v.19, supl. 2, julho 2001. CD-ROM.

CRAVEIRO, A. A.; FERNANDES, A. G.; ANDRADE, C. H. S.; MATOS, F. J. A.; ALENCAR, J. W.; MACHADO, M. I. L. Óleos essenciais de plantas do nordeste. Fortaleza: Ed. UFC, 1981.p.63.

DELOUCHE, J. C. An accelerated aging techniques for predicting the relative storability of crimson clover and tall fescue seed lots. Agronomy Abstracts, Madison, p.40, 1965.

DELOUCHE, J. C.; BASKIN, C.C. Accelerated aging techniques for predicting the relative storability of seeds lots. Seed Science and technology, Zurich, v.1, n.2, p.427552, 1973.

DELOUCHE, J. C.; HELMER, J. D. Predicting the longevity of alfafa and lettuce seed lots. In: ANNUAL CONFERENCE, 64. 1967, Local. Proceedings... Local: Editora, 1967.p.

IRIGON, D. L.; ROSSINI, M. C. Aferição de testes de vigor para sementes de trigo. Informativo ABRATES, Curitiba, v.3, n.1, p.7-23, 1992.

JIANHUA, Z.; McDONALD, M. B. The saturated salt accelerated aging test for small-seeded crops. Seed Science and Technology, Zurich, v.25, p.123-131, 1996.

KOSTETZER, V.; LIMA, C. B.; SATO, O.; BUENO, J. T.; BELLETTINI, N. M. T.; LEITE, L. L.; BERTHI, D.; SILVA, M. Incidência de fungos em sementes de camomila durante teste de envelhecimento acelerado. In: WORKSHOP DE PLANTAS MEDICINAIS DE BOTUCATU, 6., 2004. Botucatu. Anais... Botucatu, 2004a. p. 24.

KOSTETZER, V.; LIMA, C. B.; SATO, O.; BUENO, J. T.; BELLETTINI, N. M. T.; LEITE, L. L.; BERTHI, D.; SILVA, M. Incidência de fungos em sementes de erva cidreira verdadeira durante teste de envelhecimento acelerado. In: WORKSHOP DE PLANTAS MEDICINAIS DE BOTUCATU. 6., 2004, Anais... Botucatu: Unesp, 2004b. p.25.

KRZYZANOWSKI, F. C. A técnica de envelhecimento precoce na avaliação do vigor de lotes de sementes de feijoeiro (Phaseolus vulgaris L.). 1974. Tese (Mestrado em Agronomia)- Escola Superior de Agronomia Luiz de Queiroz, Universidade de São Paulo, Piracicaba.
LEITE, L. L.; LIMA, C. B.; SATO, O.; BUENO, J. T.; BERTHI, D.; SILVA, M.; KOSTETZER, V.; CAPELOSSA, M. I. Incidência de fungos em sementes de espinheira santa durante teste de envelhecimento acelerado. Arquivos APADEC, Maringá, v.8, Sup.1, p.28, out., 2004.

LORENZI, H.; MATOS, F. J .A. Plantas medicinais no Brasil: nativas e exóticas. São Paulo: Plantarum, 2002. p.253.

MARCOS FILHO, J. Teste de envelhecimento acelerado. In: KRZYZANOWSKI, F. C.; VIEIRA, R. D.; FRANÇANETO, J. B. (Ed.). Vigor de sementes, conceitos e testes. Londrina: ABRATES, 1999.

MARCOS FILHO, J. Teste de envelhecimento acelerado. In: VIEIRA, R. D.; CARVALHO, N. M. Teste de vigor em sementes. Jaboticabal: FUNEP, 1994.

MARCOS FILHO, J.; SHIOGA, P. S. Tratamento fungicida de sementes de soja no teste de envelhecimento rápido. Revista de Agricultura, Piracicaba, v.56, n.3, p.163-172, 1981.

MARTINS, C. C.; MARTINELLI-SENEME, A.; CASTRO, M. M.; NAKAGAWA, J.; CAVARIANI, C. Comparação entre métodos para a avaliação do vigor de lotes de sementes de couve-brócolos (Brassica oleracea L. var. itálica PLENK). Revista Brasileira de Sementes, Brasília, v.24, n.2, p.96-101, 2002.

MATTOS, S. H.; INNECCO, R.; CRUZ, G. F.; EHLERT, P. A. D. Determinação da altura de corte em alfavaca cravo. In: CONGRESSO BRASILEIRO DE OLERICULTURA, 40., 2000, Brasília: Anais... Brasília, 2000. p.998-999.

MELLO, S. C.; SPINOLA, M. C. M.; MINAMI, K. Métodos de avaliação da qualidade fisiológica de sementes de brócolos. Scientia Agrícola, Piracicaba, v.56, n.4 (sup.), p.1151-1155, out./dez. 1999.

MELLO, V. D. C.; TILLMANN, M. A. A. O teste de vigor em câmara de envelhecimento precoce. Revista Brasileira de Sementes, Brasília, v.9, n.2, p.93-102, 1987.

MENEGHELLO, G. E.; SCHNEIDER, S. M. H.; LUCCAFILHO, O. A. Veracidade da germinação indicada nas embalagens de sementes de espécies medicinais. Revista Brasileira de Sementes, Brasília, v.24, n.1, p.5-10, 2002.

MIRANDA, D. M.; NOVEMBRE, A. D. L. C.; CHAMMA, H. M. C. P. Avaliação do potencial fisiológico de sementes de sorgo pelo teste de envelhecimento acelerado. Revista Brasileira de Sementes, Brasília, v.23, n.1, p.226-231, 2001.

NÓBREGA, L. H.P.; CORRÊA-JÚNIOR, C.; RODRIGUES, T. J. D.; CARREGARI, S. M. R. Efeito da luz e da temperatura na germinação de camomila (Matricaria recutita). Revista Brasileira de Sementes, Brasília, v.17, n.2, p.137-140, 1995. 
PANOBIANCO, M.; MARCOS FILHO, J. Envelhecimento acelerado e deterioração controlada em sementes de tomate. Scientia Agrícola, Piracicaba, v.58, n.3, p.525-531, jul./set. 2001.

POWELL, A. A. The controlled deterioration test. In: VAN de VENTER, H. A. (Ed.). Seed vigour testing seminar. Copenhagen: ISTA, 1995. p.73-87.

ROCHA, F. R.; CHAVES, F. C. M.; SCARDA, F. M.; MING, L. C. O fitocromo e a influência da luz na germinação e vigor de sementes de alfavaca-cravo sob condições de alta irradiância. Horticultura Brasileira, Brasília, v.18, julho 2000.

RODO, A. B.; MARCOS FILHO, J. Accelerated aging and controlled deterioration for the determination of the physiological potential of onion seeds. Scientia Agrícola, Piracicaba, v.60, n.3, p.465-469, jun./set. 2003.

RODO, A. B.; PANOBIANCO, M.; MARCOS FILHO, J. Metodologia alternativa do teste de envelhecimento acelerado para sementes de cenoura. Scientia Agrícola, Piracicaba, v.57, n.2, p.289-292, abr.jun. 2000.

ROSA, S. G. T.; FERREIRA, A. G. Germinação de sementes de espécies medicinais do Rio Grande do Sul: Bromélia anticantha patens (Jacq.) Willdenow. Acta Botânica Brasileira, São Paulo, v.12, n.3 (sup.), p.515-522, 1998.

ROSSETO, C. A. V.; BASSIN, C. A.; CARMO, M. G. F.; NAKAGAWA, J. Tratamento fungicida, incidência de fungos e momento de avaliação da germinação no teste de envelhecimento acelerado em sementes de amendoim. Revista Brasileira de Sementes, Brasília, v.23, n.2, p.7887,2001.
ROSSETO, C. A. V.; MARCOS FILHO, J. Comparação entre os métodos de envelhecimento acelerado e de deterioração controlada para avaliação da qualidade fisiológica de sementes de soja. Scientia Agrícola, Piracicaba, v.52, n.1, p.123-131, 1995.

RUSHING, T. T. Evaluation of methods for predicting storage potential of tall fescue, crimson clover, sorghum and wheat seed lots. 1969.Thesis (Doutorado em ) Mississippi State University, Mississippi.

SANTOS, P. M.; GONDIM, T. C. O.; ARAÚJO, E. F.; DIAS, D. C. F. S. Avaliação da qualidade fisiológica de sementes de milho-doce pelo teste de envelhecimento acelerado. Revista Brasileira de Sementes, Brasília, v.24, n.1, p.9196, 2002.

SILVA, M. A. D.; SILVA, W. R. Comportamento de fungos e de sementes de feijoeiro durante o teste de envelhecimento artificial. Pesquisa Agropecuária Brasileira, Brasília, v.35, n.3, p.599-608, 2000.

TORRES, S. B. Teste de envelhecimento acelerado em sementes de erva-doce. Horticultura Brasileira, Brasília, v.22, n.2, sup.2, jul. 2004. CD-ROM.

TORRES, S. B.; MARCOS FILHO, J. Teste de envelhecimento acelerado em sementes de maxixe (Cucumis anguria L.). Revista Brasileira de Sementes, Brasília, v.23, n.2, p.108-112, 2001. 